\title{
The medial malleolar network: a constant vascular base of the distally based saphenous neurocutaneous island flap
}

\author{
F.T. Ballmer ${ }^{1}$, R. Hertel ${ }^{1}$, H.P. Noetzli ${ }^{1}$ and A.C. Masquelet ${ }^{2}$ \\ Department of Orthopaedic Surgery, University of Berne, Inselspital, CH-3010 Berne, Switzerland \\ ${ }^{2}$ Service de Chirurgie Orthopëdique et Réparatrice, Hôpital Avicenne, 125, route de Stalingrad, F-93000 Bobigny, France
}

Summary: Based on 30 fresh cadaver dissections a detailed anatomic study of the medial malleolar network is presented with particular attention to the anastomoses between the latter and the vascular axis that follows the saphenous nerve. The medial malleolar network is formed by the anterior medial malleolar artery, branches from the medial tarsal arteries, the posterior medial malleolar artery and branches from the medial plantar artery. A distinct anterior medial malleolar artery and posterior medial malleolar artery could be identified in 80 and $20 \%$, respectively, as well as constant additional small branches arising from the anterior tibial or posterior tibial artery. A constant anastomosis was found between the arcade formed by the medial tarsal arteries and the medial plantar a. in $60 \%$, and the medial branch of the medial plantar artery in $40 \%$, respectively. This anastomosis always gave rise to branches to the medial malleolar network. In the perimalleolar area and with regard to the great saphenous $v$. a larger anterior and a smaller posterior branch of the saphenous nerve was found in 100 and $90 \%$, respectively. In all dissections, for both branches of the saphe-

Correspondence to: F.T. Ballmer nous nerve two to four small, but distinct anastomoses between the medial malleolar network and the perineural vascular axis were identified. These constant anastomoses represent a new and reliable vascular base for the distally-based saphenous neurocutaneous island flap. Thus, the pivotal point of the flap can be chosen in the area of the medial malleolus without respecting the most distal septocutaneous anastomosis between the perineural vascular axis and the posterior tibial artery. Additionally, an illustrative clinical case is presented.

Le réseau malléolaire médial, origine constante du lambeau en îlot neuro-cutané saphène à pédicule distal

Résumé : À partir de la dissection de 30 pièces cadavériques fraîches, nous avons réalisé une étude anatomique détaillée du réseau malléolaire médial, particulièrement orientée sur les anastomoses entre ce dernier et l'axe vasculaire qui suit le nerf saphène. Le réseau malléolaire médial est formé par l'artère malléolaire médiale antérieure, les branches des artères tarsales médiales, l'artère malléolaire médiale postérieure et des branches de l'artère plantaire médiale. Une artère malléolaire médiale antérieure et une artère malléolaire médiale postérieure distinctes ont pu être identifiées dans respectivement 80 et $20 \%$ des cas, en plus de l'apport constant réalisé par de fines branches issues des artères tibiales antérieure et postérieure. Nous avons trouvé une anastomose constante entre l'arcade formée par les artères tarsales médiales et l'artère plantaire médiale dans $60 \%$ des cas, la branche médiale de l'artère plantaire médiale dans $40 \%$ des cas. Cette anastomose donnait toujours naissance à des branches alimentant le réseau malléolaire médial. Dans la région péri-malléolaire et en regard de la veine grande saphène, nous avons trouvé respectivement dans 100 et $90 \%$ des cas deux branches de division du nerf saphène, une branche antérieure plus volumineuse et une branche postérieure plus petite. Sur toutes les dissections nous avons identifié, pour chacune des branches de division du nerf saphène, deux à quatre anastomoses distinctes entre le réseau malléolaire médial et l'axe vasculaire péri-neural. Ces anastomoses constantes représentent une origine vasculaire fiable nouvellement identifiée pour la réalisation d'un lambeau en îlot neuro-vasculaire saphène à pédicule distal. Le point de rotation de ce lambeau peut être choisi au niveau de la région malléolaire médiale, sans respecter les anastomoses septocutanées les plus distales entre l'axe vasculaire péri-neural et l'artère tibiale postérieure. Un cas clinique illustrant ce lambeau est présenté. 
Key words: Medial malleolar network - Saphenous nerve - Neurocutaneous flap - Island flap - Lower limb

At the turn of the century Quénu and Lejars demonstrated that cutaneous nerves are accompanied by a vascular axis, and in 1936, Salmon mentioned neurocutaneous arteries without giving details $[26,30]$. In the late seventies, the saphenous $n$. was believed to be the best suited free vascularized nerve graft based on studies on the vascularization of several nerves $[7,33]$. But although the intimate relationship between the sensory nerves and the skin had been known for a long time, only recently has the concept of neurocutaneous island flaps for coverage of soft-tissue defects been developed and clinically applied $[5,21]$. The initial anatomic studies on neurocutaneous flaps showed that the vascular axis that follows a superficial sensory nerve in its suprafascial course ensures the vascularization of the nerves and gives off several cutaneous branches to supply the skin. The vascular network of the nerve itself, which can be either a true artery or an interlacing network, is fed by anastomoses with septocutaneous vessels issuing from a deep main vessel or direct cutaneous arteries [21]. For the vascular axis of the saphenous n. two to seven septocutaneous anastomoses with the posterior tibial artery along its course in the leg have been identified. The most distal anastomosis is located 3 to $5 \mathrm{~cm}$ proximal to the medial malleolus. Thus, this area corresponds to the most distal pivotal point of the original distally based saphenous neurocutaneous island flap relying on a septocutaneous vessel $[8,21]$. As the saphenous $\mathrm{n}$. passes anterior to the medial malleolus to the dorsum of the foot, it was hypothesised that reliable anastomoses between the medial malleolar network and the vascular axis of the saphenous n. may exist. Consequently, the pivotal point of a distally based saphenous neurocutaneous island flap could be chosen in the area of the medial malleolus without identifying or respecting the most distal septocutaneous anastomosis between the vascular axis of the saphenous $\mathrm{n}$. and the posterior tibial a. Thus, the dissection would be fairly easy consisting of elevation of a broad subcutaneous fascial pedicle, which includes the branches of the saphenous $\mathrm{n}$. with the perineural vascular axes and the saphenous v. Additionally, the more distally located pivotal point would lengthen the pedicle of the flap. Therefore, the purpose of the study was to examine in detail the anatomy of the medial malleolar vascular network with particular attention to the anastomoses of the latter with the vascular axis that follows the saphenous $n$.

\section{Material and methods}

The anatomic study was performed on 30 fresh cadaver lower limbs of both sexes. The mean age at death ranged from the fifth to the ninth decade. Both legs were injected with coloured neoprene latex via the femoral artery. The injection was continued until the capillary beds of the toes were seen to fill. Limbs lacking in good peripheral staining were excluded. The cadavers were subsequently refrigerated, and dissections under loupe magnification were carried out after 2 days.

With the cadaver in the supine position, an anterior incision was made from the middle third of the leg to the metatarsal region and the skin was carefully dissected off. While respecting the saphenous $n$. , including its vascular axis and the great saphenous $v$., the fascia and the retinacula were opened and removed as well as tendons and muscles if required for better exposure. During the subsequent careful dissection the anatomical structures listed below were identified and analysed. In particular the medial malleolar network (MMN), and the blood supply to the vascular axis of the saphenous $\mathrm{n}$. were studied. The acronyms of the anatomic structures described below and shown in Fig. 1 are listed at the table 1.

The following data were recorded:

a) the presence or absence of the anterior tibial a. (ATA) and dorsalis pedis a. (DPA), respectively, and their location with respect to the transverse bimalleolar axis;

b) the presence or absence of the anterior medial malleolar a. (AMMA); if present, its location with respect to the ankle joint-line, as well as the number of additional smaller vessels present; c) the presence or absence of the medial tarsal a. (MTA); if present, the number of vessels as well as the presence or absence of anastomosis of the MTA with the MMN and the medial plantar a. (MPA);

d) the presence or absence of the posterior tibial a. (PTA);

e) the presence or absence of the posterior medial malleolar a. (PMMA); if present, its location with respect to the ankle joint-line, as well as the number of additional smaller vessels present;

f) the diameter at its origin of the DPA (at the level of the ankle joint-line), AMMA, MTA, PTA, PMMA;

g) the presence or absence of the saphenous n. (SN) at the level of the ankle joint-line; if present, the number of branches and location with respect to the great saphenous v. (GSV);

h) the presence or absence of anastomosis between the MMN and the vascular axis of the SN.

The anatomic study is supplemented by an illustrative clinical case.

\section{Results}

Anterior tibial a. (ATA) and dorsalis pedis a. (DPA) (Figs. 1,2)

The DPA was the continuation of the ATA in 27 of the 30 dissections (90\%). In $2 / 30$ specimens ( $7 \%$ ) the DPA and the perforating branch of the peroneal a. were of a similar calibre, and in $1 / 30$ limbs $(3 \%)$ only a narrow DPA was found. The mean diameter of the DPA at the level of the ankle joint interline was $2.1 \mathrm{~mm}$ (range, 0.8 to $3.5 \mathrm{~mm}$ ). In $11 / 30$ dissections (37\%) the distal ATA was located laterally to the middle of the transverse bimalleolar axis (Fig. 2).

\section{Anterior medial malleolar a. (AMMA)}

(Figs. 1, 2)

In $24 / 30$ specimens $(80 \%)$ a distinct branch was identified as the AMMA, which travelled medially and branched while joining the MMN. The mean diameter of this vessel at its origin was $0.5 \mathrm{~mm}$ (range, 0.3 to $0.7 \mathrm{~mm}$ ). The artery was located between approximately the ankle joint interline and up to $4 \mathrm{~cm}$ 


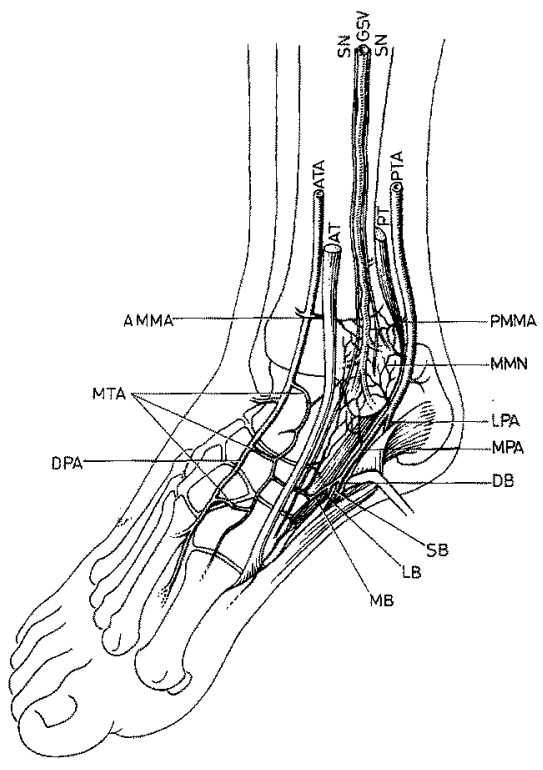

Fig. 1. Schematic drawing of the anatomy of the medial malleolar area, especially of the vascular branches forming the medial mallcolar network. The vascular axes of the two branches of the saphenous nn. and their anastomoses with the medial malleolar network are not shown $(A T$, tibialis anterior $\mathrm{m}$; $P T$, tibialis posterior $\mathrm{m}$.; other abbreviations are listed in table 1)

Table 1. Acronyms of the anatomic structures in alphabetical order (Fig. 1, 5c, 6a,b)

$A M M A$, anterior medial malleolar artery; $A T A$, anterior tibial artery; $D B$, deep branch of the MPA; $D P A$, dorsalis pedis artery; $G S V$, great saphenous v.; $L B$, lateral branch of the $\mathrm{DB} ; M B$, medial branch of the DB; $M M N$, medial malleolar network; $M P A$, medial plantar artery; MTA, medial tarsal artery; $P M M A$, posterior medial malleolar artery; $P T A$, posterior tibial artery; $S N$, saphenous n.; $S C A$, septocutaneous anastomosis; $S B$, superficial branch of the MPA

proximally. Besides this main vessel, up to three small branches arose from the ATA travelling medially to join the MMN.

\section{Medial tarsal aa. (MTA) (Figs. 1, 2)}

From its medial side, the DPA gave two to four branches: the average diameter at their origin measured $0.4 \mathrm{~mm}$ (range, 0.2 to $0.7 \mathrm{~mm}$ ). Those branches given off at the level of the cuneiform bones and the navicular were the most prominent. The branches divided to form a vascular arca- de with each other always anastomosing with the MMN. Additionally, in all dissections this arcade anastomosed with the MPA or the medial branch of the MPA (see also section MPA).

\section{Posterior tibial a. (PTA) (Figs. 1,3)}

The PTA was present in all limbs. The mean diameter of the PTA $4 \mathrm{~cm}$ proximal to the tip of the medial malleolus was $2.7 \mathrm{~mm}$ (range, 1.2 to $3.9 \mathrm{~mm}$ ). In its retromalleolar course the PTA gave off a variable number of small branches to the MMN. Deep to the flexor retinaculum the PTA divided into the medial and lateral plantar aa.

\section{Posterior medial malleolar a. (PMMA)} (Figs. 1,3)

In only $6 / 30$ dissections ( $20 \%$ ) could a dominant vessel with a mean diameter of $0.4 \mathrm{~mm}$ be identified as the PMMA. Totally, the PTA gave off 2 to 4 small branches (mean diameter $0.25 \mathrm{~mm}$ ) one to four $\mathrm{cm}$ proximal to the tip of the medial malleolus. The branches travelled around the medial malleolus anastomosing with each other to join the $\mathrm{MMN}$.

\section{Medial plantar a. (MPA) (Figs. 1, 3)}

The MPA travelled in the medial compartment of the sole of the foot covered by abductor hallucis; it was present in all limbs. It divided into two branches, superficial (SB) and deep (DB). The deep branch in turn divided into two further branches: a lateral branch (LB) and a medial branch (MB) which crossed the terminal part of the tibialis posterior tendon to run distally along the medial margin of the foot. This pattern was seen in 25/30 dissections (83\%). In 5/30 limbs (17\%) the medial branch of the deep branch of the MPA arose directly from the MPA.

In $12 / 30$ specimens (40\%) an anastomosis with a mean diameter of $0.5 \mathrm{~mm}$ (range, 0.3 to $0.7 \mathrm{~mm}$ ) was found between the medial branch of the MPA and the vascular arcade formed by the MTA. In $18 / 30$ specimens $(60 \%)$, the anastomosing vessel with the MTA arose directly from the MPA (Fig. 3).
In all dissections the medial malleolar network received branches from the MPA and the anastomosis between the MPA and MTA.

\section{Saphenous n. (SN) (Figs. 1,4)}

In the area of the medial malleolus, anterior to the great saphenous $v$. (GSV), a large branch of the saphenous $n$. could be identified in all dissections, passing distally to reach the medial side of the dorsum of the foot. In all but three of the 30 dissections (90\%) a smaller branch could also be found, which is closer and posterior to the GSV. This posterior branch terminated at about the level of the ankle. All dissected nerves were well vascularized by a rich vascular axis that showed good filling (Fig. 4). The two branches of the SN together with the GSV were intimately related to the MMN. In all dissections for both branches of the saphenous n. two to four small, but distinct anastomoses between the MMN and the perineural vascular axis were identified. In its course from the ankle joint-line to the cuneonavicular articulation the anterior branch of the SN variably received additional small branches from the arcade formed by the MTA.

\section{Clinical application}

A 50-year old patient presented with a chronic ulcer in the area of the medial malleolus, whereby the anterior margin of the defect is located posteriorly to the course of the GSV as well as the anterior branch of the SN. The anterior feeding vessels of the medial malleolar network, i.e. the anterior medial malleolar a. and the medial tarsal aa. are preserved. The course of the great saphenous v., and consequently of the branches of the saphenous $\mathrm{n}$. is marked over the lower medial aspect of the leg. The design of the flap is outlined on this course according to the size of the defect and the required length of the pedicle (Fig. 5a). An island flap of $6 \times 5 \mathrm{~cm}$ is elevated and includes the fascia. The subcutaneous fascial pedicle is elevated after performing two skin flaps by subdermal dissection. The pedicle should have a width of 2 to $3 \mathrm{~cm}$ to include the branches of the $\mathrm{SN}$ with the perineural 


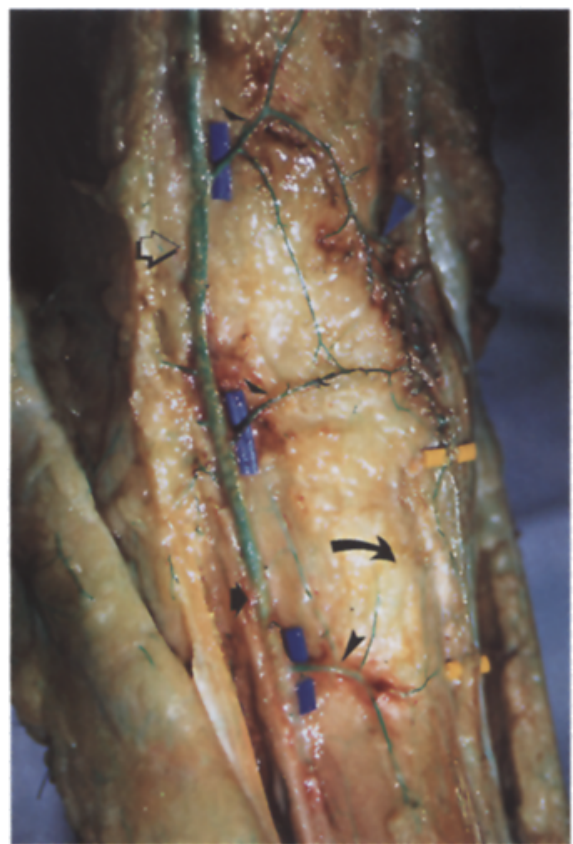

Fig. 2. Dorsal ankle area of left foot (bottom, distal leg; top, mid-foot; on the right, medially). Anterior tibial a. (black arrow), anterior medial malleolar a. (long arrowhead), dorsalis pedis a. (hollow arrow), medial tarsal aa. (shori arrowheads) forming an arcade as well as an anastomosis (blue arrow) with the medial plantar a. Medial malleolar area (curved arrow) with stained vascular axis of the anterior branch of the saphenous $\mathrm{n}$. (yellow rubber strips)

vascular axes and the GSV. The septocutaneous anastomoses to the posterior tibial a. are not respected on the posterior margin of the pedicle. The perfusion of the pedicle relies on a retrograde flow in the perineural vascular axis, which is fed by the anterior anastomoses of the medial malleolar network. Therefore, no dissection is carried out in the medial premalleolar area to avoid any surgical trauma. At the proximal end of the flap the $\mathrm{v}$. is ligated and cut, and the $n$. branches are severed (Fig. $5 \mathrm{~b}$ and c). The donor site of the skin paddle and the pedicle are covered with split-thickness skin grafts. The postoperative course was uneventful. The final result is excellent (Fig. 5d).

\section{Discussion}

In various standard textbooks of anatomy the medial malleolar network and the saphenous n. are described, however neither anatomic details nor the presence or absence of vascular anastomoses bet-

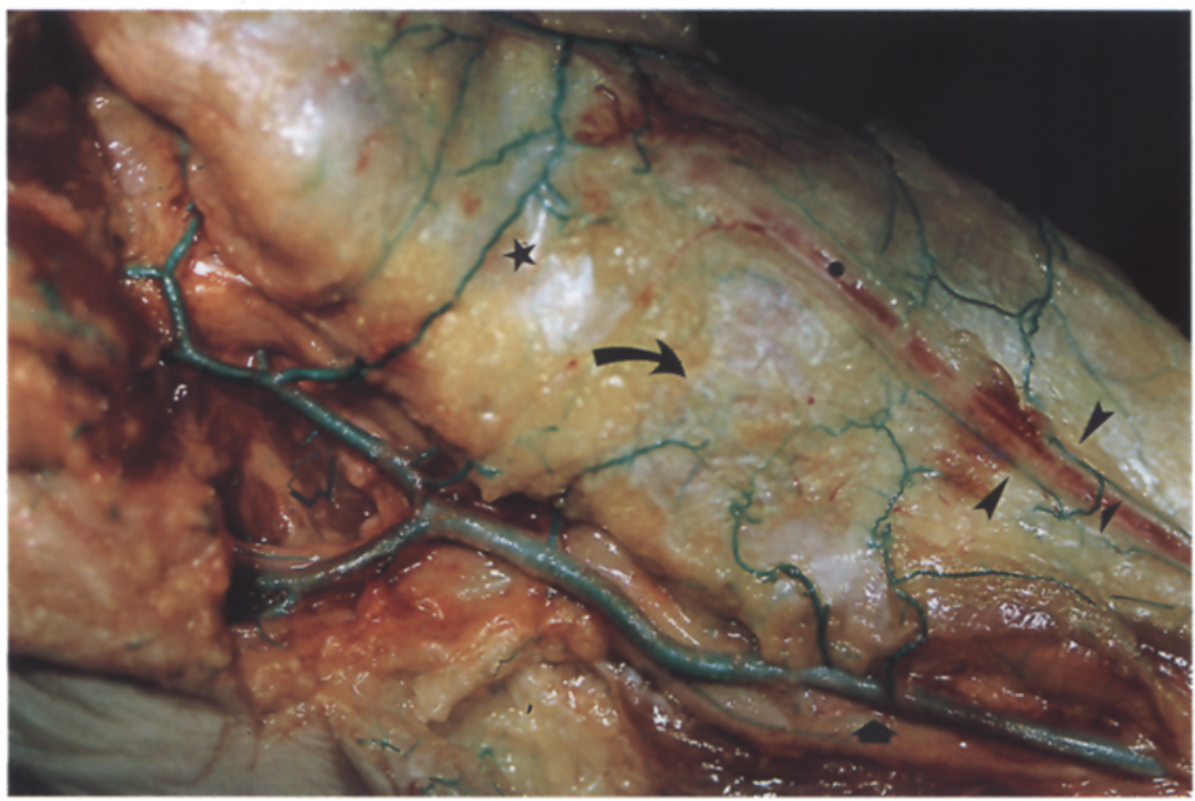

Fig. 3. View of right medial malleolar area (on the right, distal leg; top left, mid-foot; bottom left, heel). Medial malleolar network (curved arrow) recieving branches from the posterior tibial a. (black arrow), medial plantar a. (hollow arrow), anastomosis (star) between the medial plantar and medial tarsal aa. Great saphenous v. (dot). Note distinct anastomosis (short arrowhead) between the vascular axes of the saphenous $\mathrm{n}$. branches (long arrowheads) as well as the medial malleolar network

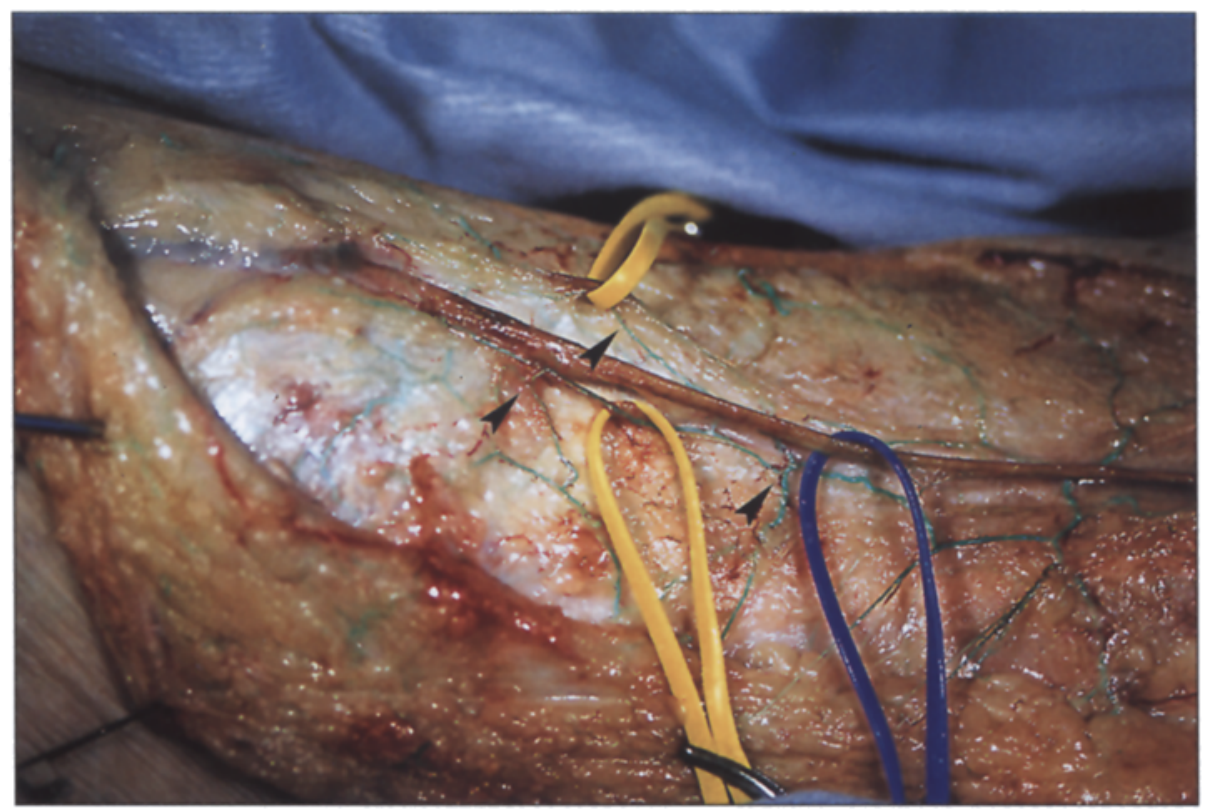

Fig. 4. View of right medial malleolar area (on the right, distal leg; on the left, midufoot; bottom left, heel). Vascular anastomoses (arrowheads) between saphenous n. branches with stained vascular axes (yellow rubber bands) and the medial malleolar network. Great saphenous v, (blue rubber band)

ween the two structures are given $[12$, $25,32,34,36]$. A possible explanation for that deficit might have been absence of clinical relevance in the past. However, with the recent development of the concept of neurocutaneous island flaps our attention has been drawn to this area and has stimulated us to perform a detailed anatomic study.

Some findings of the present study need further discussion. In the dissected limbs, the incidence of the dorsal pedis a. as the continuation of the anterior tibial a., as well as its location with respect to 

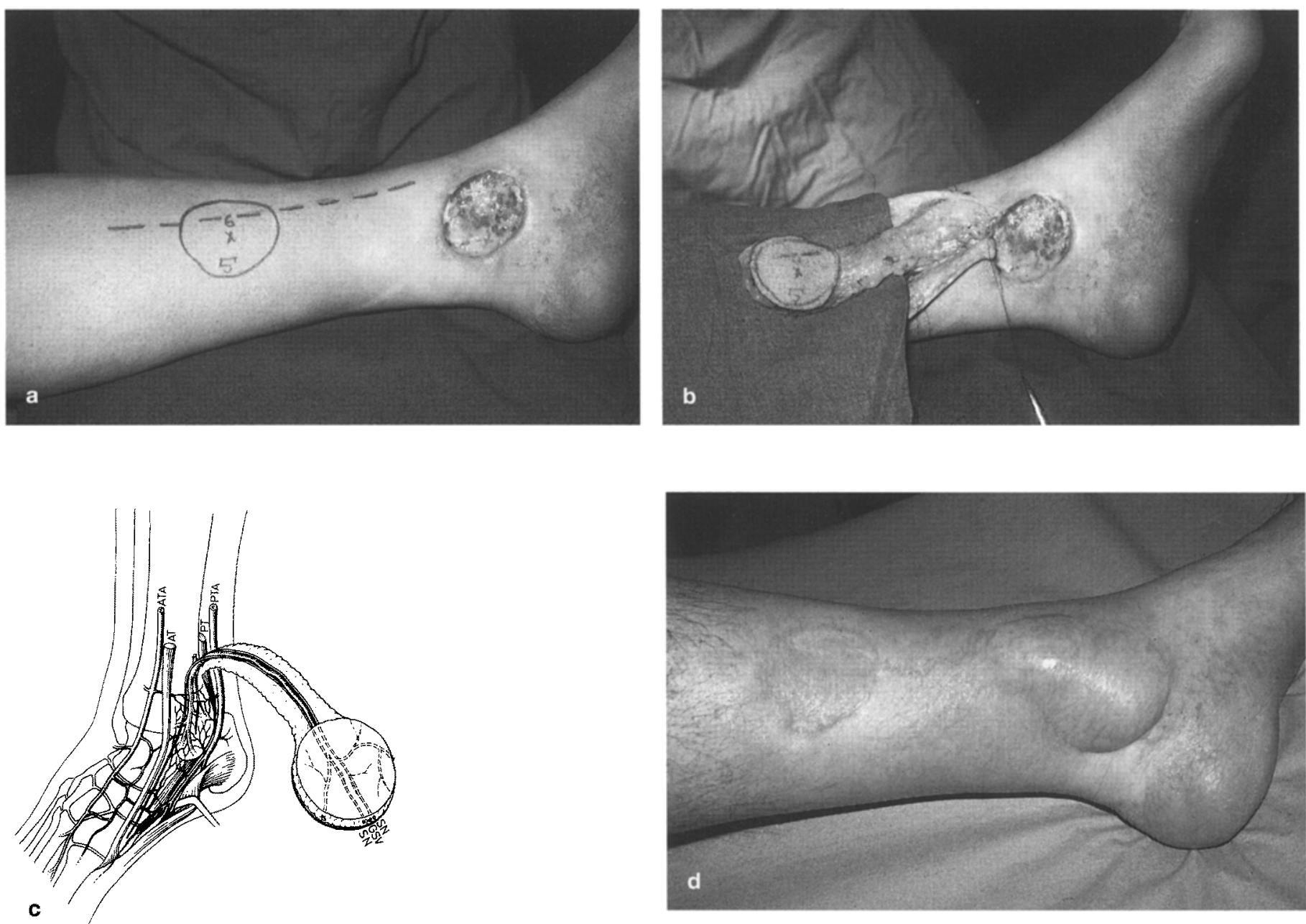

Fig. Sa-d. a Chronic ulcer in the medial malleolar area. Outline of a $6 \times 5 \mathrm{~cm}$ island flap and of the course of the great saphenous v, and of the anterior saphenous n., which are located anterior to the ulcer. The anterior feeding vessels of the medial malleolar network, i.e. the anterior medial malleolar a. and the medial tarsal aa. are preserved; $\mathbf{b}$ Note the width of the subcutaneous fascial pedicle, which includes the branches of the saphenous $\mathrm{n}$. with the perineural vascular axes and the saphenous v. Deliberately, no dissection is carried out in the medial premalleolar area to avoid any surgical trauma to the anterior feeding vessels of the medial malleolar network; $\mathbf{c}$ Schematic drawing of an elevated distally based saphenous neurocutaneous island flap relying on the medial malleolar network. The vascular axes of the two saphenous nerve branches and their anastomoses with the medial malleolar network are not shown (AT, tibialis anterior m.; PT, tibialis posterior m.; other abbreviations are listed in table 1); $\mathbf{d}$ Final result after uneventful postoperative course

the transverse bimalleolar axis, are in agreement with the literature $[15,22,37]$. In none of our specimens was the dorsal pedis a. totally absent, in contrast to some published data indicating the "absence" of the dorsal pedis a. in $2.25 \%$ and $14.2 \%$ of specimens $[10,15,22,23$, $27,28,31]$. However, a close analysis of the literature reveals that in those series with the highest incidences of "absence" not only absent but also small arteries were excluded $[15,27,37]$. Even a total absence of the dorsal pedis a. would not preclude a good perfusion of the medial malleolar network as it is constantly supplied from the posterior tibial and medial plantar aa. In our dissections the origin of the dorsalis pedis a. was never exclusive- ly from the perforating branch of the peroneal a. as described in up to $7.7 \%$ of specimens in the literature $[1,15,24]$. However, we found in $7 \%$ the dorsalis pedis a. and the perforating branch of the peroneal a. to be of about the same calibre. Pachnik et al described this patterm in $2 \%$ [24].

There is some difficulty in deciding which vessel should be called the anterior medial malleolar a. In this respect we agree with Huber [15]. However, our study revealed in $80 \%$ of cases a distinct branch as well as several smaller branches. Our findings are consistent with other investigations who observed malleolar branches originating from the level of the ankle joint-line to about $5 \mathrm{~cm}$ proximal to it $[6,11,12,17$, $19,34]$.

In our specimens a constant anastomosis between the first medial tarsal aa. and the medial malleolar network was identified. While Wildenauer also regularly found this connection, Bailleul et al. described it in only $82 \%[2,35]$.

The anastomosis between the medial tarsal and the medial plantar aa. has been described by several authors $[3,20,29$, $31,35]$. An extensor digitorum brevis flap was designed based on this constantly present vessel [3]. Our dissections revealed that the anastomosis arose in $60 \%$ directly from the medial plantar a. and in $40 \%$ from the medial branch of the medial plantar a. 
The posterior tibial a. was substantial and always present in our specimens. This is in agreement with the literature, which indicates an absent posterior tibial pulse in less than $1 \%$ [28]. The posterior medial malleolar a. is described as a single vessel $[12,31]$. In our specimens a distinct posterior medial malleolar a. could be defined in only $20 \%$, but as well as this main vessel there were always present several small branches to the medial malleolar network issuing from the posterior tibial a.

The pattern of division of the medial plantar a. does not vary significantly from other reports $[20,29,31]$.

The constant pattern of two main branches of the saphenous $n$. at the level of the ankle is confirmed [12, 14]. In all our specimens a substantial number of small vascular anastomoses could be identified between the branches of the saphenous $\mathrm{n}$. and the medial malleolar network. To the best of our knowledge, these have not been previously described in the literature. These constant and reliable anastomoses represent a new vascular base for the distally based saphenous neurocutaneous island flap.

The originally designed flap is dependent on septocutaneous anastomoses with the posterior tibial a. (Fig. 6a). The most distal of such perforating branches is located 3 to $5 \mathrm{~cm}$ proximal to the medial malleolus, and is considered to be the most distal pivotal point of a distally based saphenous neurocutaneous island flap (Fig. 6b) $[8,21]$. However, the use of the vascular base of the medial malleolar network facilitates dissection as identification and preservation of the most distal septocutaneous anastomosis is avoided. The dissection consists of a safe elevation of a broad subcutaneous fascial pedicle, which includes the branches of the SN with the perineural vascular axes and the GSV. To avoid surgical trauma to the feeding medial malleolar network, any dissection in the malleolar area should be avoided. Additionally, the more distally located pivotal point appreciably lengthens the pedicle of the flap (Fig. 5c, 6b).

The aforementioned statements may widen the spectrum of indications for this flap which already has some prominent advantages, e.g. simple and rapid eleva-
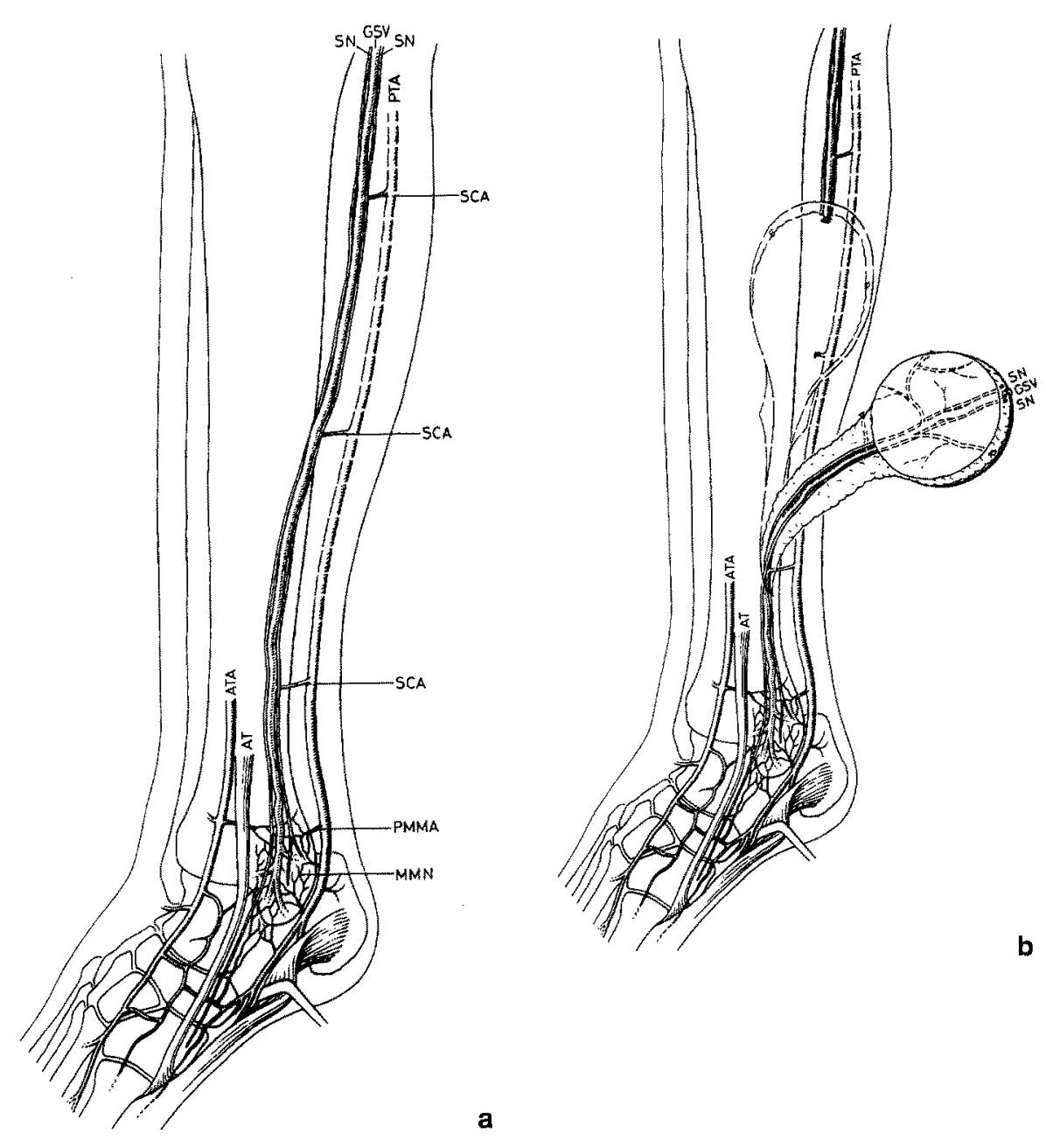

Fig. 6a, b. a Drawing of the saphenous v. and three septocutaneous anastomoses between the saphenous nn. and the posterior tibial a. [21]. The perineural vascular axes are not shown (AT, tibialis anterior $\mathrm{m}$; other abbreviations are listed in table 1 ); $\mathbf{b}$ Schematic drawing of an elevated original distally based saphenous neurocutaneous island flap relying on the nost distal septocutaneous anastomosis between the saphenous $\mathrm{nn}$. and the posterior tibial a. In comparison with Fig. $5 \mathrm{c}$ the pivotal point is appreciably more proximally located, thus shortening the pedicle of the flap (AT, tibialis anterior m; other abbreviations are listed in table 1)

tion, reliability and versatility, no sacrifice of a major artery, and one-stage procedure requiring no microsurgical technique $[8,9,13,16]$. While the sacrifice of the saphenous $\mathrm{n}$. has not been reported to be a problem in patients, the division of the great saphenous $\mathrm{v}$. may be hazardous in case of deep venous system pathology, which should be ruled out preoperatively [8].

Due to the high number of newly designed skin flaps in the last few decades, some concerns regarding the correct nomenclature and classification have been raised [18]. Although the term "neurocutaneous" is widely used in the literature, "neuroskin" or "neurovascular" could also be used for the same concept of flap $[4,5,8,9,21]$. In an effort to standardize the classification of the skin flaps, Le Nen et al. suggested that for the flap described above the term "fascio-cutaneous flap with saphenous neuro-vascular pedicle based distally" would be appropriate [18]

\section{Conclusion}

The medial malleolar network can be considered as a new and reliable vascular base for the distally based saphenous neurocutaneous island flap due to the constant vascular anastomoses between the $\mathrm{SN}$ and the medial malleolar network. Therefore, the pivotal point can be chosen in the area of the medial malleo- 
lus without identifying or respecting the most distal septocutaneous anastomosis between the perineural vascular axis and the posterior tibial a. $[8,21]$. Additionally, the more distally located pivotal point lengthens the pedicle of the flap.

Acknowledgements. This work was supported by a grant from the Swiss Orthopaedic Society (SGO), by the Department of Orthopaedic Surgery, Inselspital, University of Berne (Switzerland) and by the Laboratory of Anatomy, René Descartes University, Paris (France).

\section{References}

1. Adachi B (1928) Das Arteriensystem der Japaner. Maruzen Co., Kyoto und Tokyo

2. Bailleul JP, Olivez PR, Mestdagh H, Vilette B, Depreux R (1984) Anatomie descriptive et topographique de l'artère dorsale du pied (pédieuse). Bull Assoc Anat (Nancy) 68: 15-25

3. Bakhach $J$, Demiri E, Chahidi N, Baudet J (1998) Extensor digitorum brevis muscle flap: new refinements. Plast Reconstr Surg 102: 103-110

4. Bertelli JA (1995) Neurocutancous flaps. Plast Reconstr Surg 95: 1133-1134

5. Bertelli JA, Khoury Z (1992) Neurocutaneous island flaps in the hand: anatomical basis and preliminary results. Br J Plast Surg 45: 586 590

6. Beveridge I, Masquelet AC, Romana MC, Vinh TS (1988) Anatomic basis of a fasciocutaneous flap supplied by the perforating branch of the peroneal artery. Surg Radiol Anat 10: 195-199

7. Breidenbach WC, Terzis JK (1986) The blood supply of vascularized nerve grafts. J Reconstr Microsurg 3: 43-55

8. Cavadas PC (1997) Reversed saphenous neurocutaneous island flap: clinical experience. Plast Reconstr Surg 99: 1940-1946

9. Chang S-M (1996) The pedicle of neurocutaneous island flaps. Plast Reconstr Surg 98: 374-376
10. Chavatzas D (1974) Revison of the incidence of congenital absence of dorsalis pedis artery by an ultrasonic technique. Anat $\operatorname{Rec} 178: 289$ 290

11. Gahhos FN, Jaquith M, Hidalgo R (1989) The extended digitorum brevis muscle flap. Ann Plast Surg 23: 255-262

12. Gray H (1985) Anatomy of the human body. Thirthieth American Edition ed. Lea \& Febiger, Philadelphia

13. Hasegawa M, Torii S, Katoh H, Esaki S (1994) The distally based superficial sural artery flap. Plast Reconstr Surg 93: 1012-1020

14. Horwitz MT (1938) Normal anatomy and variations of the peripheral nerves of the leg and foot. Application in operations for vascular diseases: study of one hundred specimens. Arch Surg 36: 626-636

15. Huber JF (1941) The arterial network supplying the dorsum of the foot. Anat Rec 80 : 373-391

16. Jeng S-F, Wei F-C (1997) Distally based sural island flap for foot and ankle reconstruction. Plast Reconstr Surg 99: 744-750

17. Le Nen D, Beal D, Person H, Lefevre C, Sénécail B (1994) Anatomical basis of a fasciocutaneous pedicle flap based on the infero-lateral collateral artery of the leg. Surg Radiol Anat 16: 3-9

18. Le Nen D, Hu WG (1998) Classification des lambeaux cutanés. Mâ̂trise Orthopédique 76: $18-26$

19. Masquelet AC, Beveridge J, Romana C, Gerber C (1988) The lateral supramalleolar flap. Plast Reconstr Surg 81: 74-81

20. Masquelet AC, Romana MC (1990) The medialis pedis flap: a new fasciocutaneous flap. Plast Reconstr Surg 85: 765-772

21. Masquelet AC, Romana MC, Wolf G (1992) Skin island flaps supplied by the vascular axis of the sensitive superficial nerves: anatomic study and clinical experience in the leg. Plast Reconstr Surg 89: 1115-1121

22. Massin P, Romana C, Masquelet AC (1988) Anatomic basis of a pedicled extensor digitorum brevis muscle flap. Surg Radiol Anat 10: 267-272

23. Morrison H (1933) A study of the dorsalis pedis and posterior tibial pulses in one thousand individuals without symptoms of circula- tory affections of the extremities. N Engl J Med 208: $438-440$

24. Pachnik RL, Howard K (1977) Variations of origins of the dorsalis pedis artery. J Am Podiatr Med Assoc 67: 550-552

25. Pernkopf $E$ (1980) Atlas der topographischen und angewandten Anatomie des Menschen. 2. Auflage ed. Urban \& Schwarzenberg, München Wien Baltimore

26. Quénu J, Lejars F (1892) Etude anatomique sur les vaisseaux sanguins des nerfs. Arch Neurol (Paris) 23: 1-35

27. Reich RS (1934) The pulses of the foot. Their value in the diagnosis of peripheral circulatory disease. Ann Surg 99: 613-622

28. Robertson GSM, Ristic CD, Bullen BR (1990) The incidence of congenital absent foot pulses. Ann R Coll Surg Eng1 72: 99-100

29. Romana MC, Masquelet AC (1989) Vascularization of the inner border of the foot: surgical applications (24.06.88). Surg Radiol Anat 11: 177.178

30. Salmon M (1936) Les artères de la peau: Etude anatomique et chirurgicale. Masson, Paris

31. Sarrafian SK (1993) Anatomy of the foot and ankle. Descriptive, topographic, functional. Second edition ed. J. B. Lippincott Company, Philadelphia

32. Spalteholz-Spanner (1961) Handatlas der Anatomie des Menschen. 16. Auflage ed. Scheltema \& Holkema N.V., Amsterdam

33. Taylor GI, Ham FJ (1976) The free vascularized nerve graft. Plast Reconstr Surg 57: 413-425

34. Testut $L$, Latarjet A (1948) Traité d'anatomie humaine. neuvième édition ed. G. Doin \& Cie, Paris

35. Wildenauer E (1950) Die Blutversorgung des Talus, Z Anat Entwicklung 115: 32-36

36. Wolf-Heidegger $G(1962)$ Atlas of systematic human anatomy. Second edition ed. S. Karger, Basle (Swizzeriand) New York

37. Yamada T, Gloviczki P, Bower TC, Naessens JM (1993) Variations of the arterial anatomy of the foot. Am J Surg 166: 130-135

Received January 13, 1999 / Accepted in final form May 4, 1999 